PESHAWAR JOURNAL OF PSYCHOLOGY AND BEHAVIORAL SCIENCES, 2017, VOL. 3, NO. 1, 35-43

\title{
Parenting Styles, Coping Strategies and Life Satisfaction of Parents Having Children with Down Syndrome
}

\author{
Tooba Zia ${ }^{1}$ and Fozia Akram ${ }^{2}$ \\ GC University Faisalabad
}

The present study explores the relationship among Parenting styles, Coping Strategies and Life Satisfaction of parents having children with Down syndrome. Purposive sampling and comparative study were used to select the sample. A sample consisted of $(\mathrm{N}=100)$ parents mothers and fathers of Down syndrome children were taken from different government and private institutes of Faisalabad. The sample was further divided into $(n=50)$ mothers and $(n=50)$ fathers of Down syndrome children. The age range of participants was taken 30-55 years above. Parenting Styles Dimension Questionnaire (PSDQ) translated Urdu version by (Batool, 2013). Coping Response Inventory (CRI) translated Urdu version by (Mahmood \& Sheraz, 2012) and Life satisfaction scale (LSS) Urdu version translated by (Mahmood, 2013) were used for data collection. Pearson Product Moment Correlation Coefficient and Independent Sample T-Test were calculated for statistical analysis. Findings indicates that male parents of Down syndrome children scored high on Authoritative and permissive parenting styles and it's also showed that male parents of Down syndrome children have scored high on the scale of approach coping styles. Through that study it indicates that male parents use more approach coping styles than female parents. And male parents are equally satisfied with their lives. This study aims to use effective coping strategies and parenting styles to improve the quality of life of parents of those who are having children with disability. It also aims to increase the role of the clinical psychologist in the treatment of those children who are suffering from disability or psychological illness and also psych educate

$1_{\mathrm{GC} \text { University Faisalabad }}$

2Lecturer GC University Faisalabad 
parents those are directly or indirectly taking pain of their children.

Keywords: parenting styles, coping strategies, life satisfaction, down syndrome

The current study aims to explore parenting style, coping strategies and life satisfaction of parents having children with Down syndrome. This disorder is one of the most prevailing disorders in the field of psychopathology and most of the researches have been done on it to know about the causes and occurrence of this disorder which shows that it is a developmental disorder. The focus of this study is to know about the parenting style, coping strategies and life satisfaction of parents having children with Down syndrome. In abnormal psychology the Down syndrome has been taken as the reason behind the mental retardation which occurs as a result of chromosomal abnormality (Smith, Bierman \& Robinson, 1970).

Parenting styles (or child rearing) is the process of promoting and supporting the physical, emotional, social, and intellectual development of a child from infancy to adulthood (Feldman, \& Wetzel, 1990).Coping strategy is defined as the investigation of how individuals manage with actual stressors in real life contexts and how the impacts of these scenes gather (Griffith, Dubow, \& Ippolito, 2000). Life satisfaction is defined as "the ability to enjoy one's experience, accompanied by a degree of excitement" (Alston \&Dudley, 1989).

The researchers showed that generally those parents who have children with some mental disability usually experienced a lot of mental disturbance. Those parents used different kind of coping strategies in order to cope such an uncertain situations and hence the level of satisfaction is very low as compared to those parents who have normal children. Moreover, the parents have different parenting style thus the present study was conducted to see the relation between parenting style, coping strategies and life satisfaction of parents having children with Down syndrome. 


\section{Objectives}

Following are the main objectives of the study.

1. To find out the relationship between parenting style, coping strategies and life satisfaction of parents having children with Down syndrome.

2. To find out the gender difference between parenting styles, coping strategies and life satisfaction of parents having children with Down syndrome.

3. To examine demographic differences with references of gender and socio- economic status between parenting style, coping strategies and life satisfaction of parents having children with Down syndrome.

\section{Hypotheses}

1. There would be positive relationship between parenting styles, coping strategies and life satisfaction of parents having children with Down syndrome

2. There would be significant gender difference on the scores of Life satisfaction scale of parents having children with Down syndrome.

\section{Method}

\section{Participants}

The sample of current study was consisted of 100 parents having children with Down syndrome. The sample was further divided into two groups $n=50$ male parents and $n=50$ female parents. The age range of participants was from 30 to 55 years. The education level of the research

participants were Matriculation. Purposive sampling technique was used for data collection

\section{Research Design}

It was correlation and comparative study in which cross sectional research design was used. 


\section{Research Instruments}

The following instruments were used to assess Parenting Styles, Coping Strategies and Life Satisfaction of parents having children with Down syndrome.

- Parenting Styles Dimension Questionnaire (PSDQ)

- Coping Response Inventory (CRI)

- Life Satisfaction Scale (LSS)

\section{Procedure}

Sample was selected through purposive sampling from private and government institutes of Faisalabad. The informed consent was designed according to ethics of research. The ethical standards of research will be considered as the participants will be given a brief description about the research and will be insured that information kept confidential. The demographic information about variables such as age, gender, education, marital status and number of children will be gathered. The questionnaires will be used to measure the variables of parenting style, coping strategies and life satisfaction. Permission was also taken from the authorities of the concerned special institutions. Meeting with parents were held in schools with the help of heads of specific institutions. The data was collected through oral administration of questionnaire. Parents were asked to fill the questionnaire keeping in mind their special child. In the end participants will be thanked.

\section{Statistical Analysis}

Pearson product moment Correlation Coefficient was computed to determine relationship and independent sample t-test was used to find out differences in parenting styles, coping strategies and life satisfaction of parents having children with Down syndrome through SPSS.

\section{Results}

The current study is aimed to explore the Parenting Styles and its relationship with Coping Strategies and Life Satisfaction of parents of PESHAWAR JOURNAL OF PSYCHOLOGY AND BEHAVIORAL SCIENCES, 2017, VOL. 3, NO. 1, 35-43 
Down syndrome children. For the present study, a sample consisted of $(\mathrm{N}=100)$ fathers $(\mathrm{n}=50)$ mothers $(\mathrm{n}=50)$ was taken from different government and private institutes of Faisalabad. The age range of research participants taken was from (30- 55 years). The minimum education of participants was Matriculation. Purposive sampling technique was used to select the sample. Parenting Styles Dimension Questionnaire, Coping Strategies and Life Satisfaction Scale were administered for data collection. Pearson product moment correlation coefficient was computed to determine the relationship and independent sample t-test was used to explore the differences in Parenting Styles, Coping Strategies and Life Satisfaction of Down Syndrome parents through SPSS. In the present chapter, research findings are given in the form of tables.

Table 1

Relationship Between Parenting Styles, Coping Strategies and Life Satisfaction of Parents Having Children with Down Syndrome

\begin{tabular}{lcccccc}
\hline \multicolumn{1}{c}{ Variables } & 1 & 2 & 3 & 4 & 5 & 6 \\
\hline 1.Authoritative & - & $.55^{* *}$ & $.28^{* *}$ & .18 & .10 & .02 \\
2.Authoritarian & & - & $.64^{* *}$ & .15 & $.28^{* *}$ & $-.20^{*}$ \\
3.Permissive & & & - & .04 & $.31^{* *}$ & $-.27^{* *}$ \\
4.Approach coping & & & & - & $.31^{* *}$ & .10 \\
5.Avoidance coping & & & & - & -.17 \\
6.Life satisfaction & & & & & & - \\
\hline
\end{tabular}

Note. ${ }^{*} \mathrm{p}<.05^{* *} \mathrm{p}<.01 * * * \mathrm{p}<.001$

The result indicates that Authoritarian and Authoritative parenting styles are positively correlated with each other with level of significance .01 . The results also show that Permissive parenting styles is positively correlated with Authoritative and Authoritarian parenting styles Furthermore, avoiding coping styles is positively correlated with Authoritarian parenting styles and Permissive parenting styles and with Approach coping styles. Life satisfaction is negatively correlated with Authoritarian parenting styles and level of significance is .05. Life satisfaction is also negatively correlated with Permissive parenting styles 
and level of significance is .01. Moreover, the table also shows that Approach coping styles is non-significant with Authoritative, Authoritarian and Permissive parenting styles. Avoidance coping styles is non- significantly correlated with Authoritative parenting styles. Table 1 shows that Life satisfaction is non significantly correlated with Authoritative parenting styles, Approach coping styles and Avoidance coping styles.

Table 2

Comparison of Mean of Life Satisfaction of Parents Having Children with Down Syndrome of the Parents

\begin{tabular}{|c|c|c|c|c|c|c|}
\hline Variables & $M$ & $S D$ & $d f$ & t-value & $p$-value & $\begin{array}{l}\text { Cohen's } \\
d\end{array}$ \\
\hline LSS & & & \multirow[b]{3}{*}{98} & \multirow[b]{3}{*}{.031} & \multirow[b]{3}{*}{.97} & \multirow[b]{3}{*}{0.006} \\
\hline Mothers & 50.3 & 9.16 & & & & \\
\hline Fathers & 50.36 & 10.01 & & & & \\
\hline
\end{tabular}

Note. $\mathrm{CI}=$ Confidence Interval; $\mathrm{LL}=$ Lower Limit; $\mathrm{UL}=$ Upper Limit

Table 2 shows that there would be non-significant difference exist between fathers and mothers of children with Down syndrome on Life Satisfaction which shows that both parents (mothers and fathers) are same on the level of Life Satisfaction.

\section{Discussion}

The present study was focused the relationship between parenting style, coping strategies and life satisfaction of parents having children with Down syndrome. The main hypothesis of the present study was that there would be significant relationship between parenting style coping strategies and life satisfaction in parents having children with Down syndrome. The total sample size was hundred (fifty were males and fifty were females). Three standardized scales were used to measure the parenting style coping strategies and life satisfaction. Statistical Package for Social Sciences Version- 20 (SPSS-20) was used for analysis. Here the results of these hypotheses are discussed in the light of previous existing literature.

PESHAWAR JOURNAL OF PSYCHOLOGY AND BEHAVIORAL SCIENCES, 2017, VOL. 3, NO. 1, 35-43 
The first hypothesis of the present study was that there would be significant relationship between parenting style coping strategies and life satisfaction. To check this hypothesis Pearson product moment correlation was used. The result showed that there is significant relation between authoritarian parenting style and permissive parenting style. In the same way authoritarian parenting style has negative relation with flexible/ authoritative parenting style. Hence this hypothesis has accepted. There are a number of researches which showed the same results. Some of them are given below. Tam, Chong, Kadirvelu and Khoo (2012) said that there is significant relationship between parenting style and self-efficacy among adolescents. Shaw (2008) also reported that there is significant relationship between authoritarian parenting style and permissive parenting style. Dehyadegary, Nejad, Nasehzadeh and Divsalar (2014) also said that authoritarian parenting style has negative relation with self-efficacy. So these researches showed that parenting style has significant relationship with life satisfaction. Flexible parenting style is considered positive relation with life satisfaction.

The next hypothesis of the present study was that there would be significant difference on life satisfaction. Independent sample t-test was used to check this difference. The result of this hypothesis showed that there is non-significant difference between males and females on life satisfaction which means that the score of both groups are same on satisfaction with life scale. There are a number of researches which also showed that there is non-significant gender difference on life satisfaction. Inglehart, (1990) discussed in a study that in western Europe had less satisfy lives of parents but in others countries like East Asia people are completely satisfied in their lives and can't take pressure so the hypothesis is completely justified that male and female ratio have equal level of life satisfaction if females are less satisfied so fathers are less satisfied but the angel between both sides are equal. Down syndrome while those who used denial coping strategies have low life satisfaction. Haris (2011) examined the relationship between psychological distresses, stress and life satisfaction in parents having Down syndrome. The sample size of this study was 100 which consist of fifty male parent and fifty female parents. The result showed that there is significant negative relation between psychological distress and life satisfaction. More over there is significant negative relation between stress and life satisfaction.

PESHAWAR JOURNAL OF PSYCHOLOGY AND BEHAVIORAL SCIENCES, 2017, VOL. 3, NO. 1, 37-45 


\section{Limitations and Recommendations}

The present study offered many significant findings however there are some limitations which

The following are main limitations and recommendation:

- The sample size was too short in the present study the sample simulated with a large sample size in order to make more reliable and genuine simplifications

- It is recommended that guardians of disabled children should involve too as a research sample for further studies.

- It is further recommended that the present study can be suggested for the qualitative inductive research for the purpose of having detailed interview of the patients or participants for psychological counselling.

- It is recommended that different institutes, rehabilitation centres should develop for the patients and their suggestions must be kept from them for their further betterment.

- All possible demographic variables should be included in future studies.

\section{Implications of the Study}

- The relationship between parenting style, coping strategies and life satisfaction was explored.

- Parents training may be initiated by keeping the results of present study in mind.

- Seminars may be conducted for the purpose of awareness.

- Easier and Different kinds of tasks should be made for the parents having children with disabilities and at the end take their feedback in written form for their future betterment.

\section{References}

Ali, H., \&Amjad, N. (2014) Resilience and happiness in parents having children with Down syndrome. Journal of Behavioral Science, 33(12), 12-18.

Ajmal, A., \& Hanif, R. (2011). Stress and life satisfaction in parents having children with Down syndrome. Journal of Behavioral Science, 34(14), 27-32. 
Asad, A., \& Khawar, M. (2009). Life satisfaction and coping strategies in parents having Down syndrome. Journal of Clinical and Social Psychology, 23(22), 55-58.

Azmat, A., \& Knawal, F. (2009). Life satisfaction and coping strategies in parents having children with Down syndrome. Journal of Behavioral Sciences, 4(22), 44-48.

Duffy, S.A., Terrell, J.E., Valenstein, M., Ronis, D.L., Copeland, L.A., \& Connors, M. (2002). Coping strategies and life satisfaction in parents having children with Down syndrome. General Hospital Psychiatry, 24, 140-147.

Feldman, S. S., \&Wentzel, K. R. (1990). Relations among family interaction patterns, classroom self-restraint, and academic achievement in preadolescent boys. Journal of Educational Psychology, 82, 813-819.

Griffith, M.A., Dubow, E.F. \&Ippolito, M.F. (2000). Developmental and cross-situational Differences in adolescents' coping strategies. Journal of Youth and Adolescence, 29, 183-204.

Hmazan, K. (2002). Life satisfaction in parents having children with Down syndrome. Journal of Health Psychology, 18(22), 55-58.

Holder, G. (2007). Coping strategies and Happiness in parents having children with Down syndrome. Journal of Clinical Psychology, 22(34), 33-37.

Hubbs-Tait, L., Kennedy, T. S., Page, M. C., Topham, G. L., \&Harrist, A.W.(2008). Parental feeding practices predict authoritative, authoritarian, and permissive parenting styles. Journal of the AmericanDieteticAssociation, 108,11541161.doi:10.1016/j.jada.2008.04.008.

Hughes, S. O., Power, T. G., Fisher, J. O., Mueller, S., \& Nicklas, T. A. (2005).Revisiting a neglected construct: parenting styles in a childfeeding context. Appetite, 44, 32 . doi:10.1016/j.appet.2004.08.007 